\title{
Does preoperative analysis of intrahepatic venous anastomoses improve the surgeon's intraoperative decision making? Pilot data from a case report
}

\author{
Lars Fischer ${ }^{1}$, Max Schoebinger ${ }^{2}$, Jan-Oliver Neumann ${ }^{1}$, Sascha Müller ${ }^{1}$, \\ Hans-Peter Meinzer ${ }^{2}$, Markus W Büchler ${ }^{1}$ and Bruno M Schmied ${ }^{* 1}$
}

\begin{abstract}
Address: ${ }^{1}$ Department of Surgery, University of Heidelberg, INF 110, D-69120 Heidelberg, Germany and ${ }^{2}$ DKFZ (German Cancer Research Center) Heidelberg, INF 280, D-69120 Heidelberg, Germany

Email: Lars Fischer - Lars.Fischer@med.uni-heidelberg.de; Max Schoebinger - Max.Schoebinger@dkfz.de; Jan-Oliver Neumann - JanOliver.Neumann@med.uni-heidelberg.de; Sascha Müller - Sascha.Mueller@med.uni-heidelberg.de; Hans-Peter Meinzer - HansPeter.Meinzer@dkfz.de; Markus W Büchler - Markus.Buechler@med.uni-heidelberg.de; Bruno M Schmied* - Bruno.Schmied@med.uniheidelberg.de

* Corresponding author
\end{abstract}

Published: 2I August 2008

Patient Safety in Surgery 2008, 2:19 doi:10.1186/1754-9493-2-19

This article is available from: http://www.pssjournal.com/content/2/I/19

(c) 2008 Fischer et al; licensee BioMed Central Ltd.

This is an Open Access article distributed under the terms of the Creative Commons Attribution License (http://creativecommons.org/licenses/by/2.0), which permits unrestricted use, distribution, and reproduction in any medium, provided the original work is properly cited.
Received: 26 April 2008

Accepted: 21 August 2008

\begin{abstract}
Background: Three-dimensional (3D) visualization is thought to improve the anatomical understanding of clinicians, thus improving patient safety.

Case presentation: A 58-year-old male was admitted to our hospital in April 2007 with a suspected metastasis of a sigmoid cancer in the Couinaud segment (CS) 7. The anatomical situation of this patient was analyzed using both a CT scan and 3D images. The initial CT scan revealed that the proximal part of the middle hepatic vein was completely missing and the metastasis in the CS 7 was closely attached to the right hepatic vein. After analyzing additional 3D images, it became clear that due to the close proximity of metastasis and right hepatic vein, the resection of the right hepatic vein was inevitable. Based on this 3D analysis, it was decided to perform a right-sided hemihepatectomy. In this case report, 3D visualization resulted in a faster and clearer understanding of the unique anatomical situation in a patient with complicated liver anatomy than transversal CT images.
\end{abstract}

Conclusion: The here presented data shows for the first time 3D visualization of intravenous anastomoses in the human liver. The information offered by $3 \mathrm{D}$ visualization is not redundant but rather serves as a true source of additional information, indicating the potential benefit of 3D visualization in surgical operation planning.

\section{Background}

Three-dimensional (3D) visualization is thought to ameliorate anatomical understanding among surgeons as well as medical students [1-3] Better perception of anatomy improves the surgeon's ability to accurately plan and perform surgical procedures [1,4], an effect which can result in lower morbidity and mortality rates after surgical interventions. 
Our group has been working on 3D operation planning in liver surgery for many years [5-8]. Three-dimensional visualization based on CT scans is an efficient and fast tool for analyzing liver anatomy, possible resection proposals and volumetric consequences of the planned resections $[5,9,10]$. Particularly, the assessment of post-resectional functioning liver parenchyma is an important issue in planning of liver resections. Is has been shown that computer-assisted operation planning has a potential use of for assessment of functional respectability [11].

The existence of intrahepatic venous anastomoses (IVA) between the main stems of the hepatic veins (i.e. middle, right, and left) has been known for many years [12,13]. Couinaud [12] found anastomoses between intrahepatic veins in 25 out of 30 casts and such anastomoses must be considered a reality from the anatomical point of view [13]. The question whether these IVA exist only in pathological livers or also reflect physiological vascular patterns has been discussed heatedly from the beginning $[13,14]$. However, there are a few case reports describing the importance of such anastomoses under clinical conditions [15-18].

To our knowledge, this is the first published report of 3D visualization of intravenous anastomoses in the human liver. Because 3D imaging leads to a faster and easier understanding of the individual anatomical situation, it may be an appropriate tool to potentially increase patient safety not only in visceral surgery but also in other surgical areas [19-22].

\section{Case presentation Description of the patient}

A 58-year-old male was admitted to our hospital in April 2007 with a suspected metastasis of a sigmoid cancer in the Couinaud segment (CS) 7 found during a follow-up examination using ultrasound. The patient had undergone a resection of the colon sigmoideum due to carcinoma in 2003. In addition to the liver metastasis, the patient suffered from mild hypertension and non-insulindependent diabetes mellitus. The only preoperative imaging was an abdominal ultrasound; thus, an additional CT scan of the abdomen was performed in preparation for the surgical intervention. The metastasis in the CS 7 had a size of $2.2 \times 2.4 \mathrm{~cm}$ and was closely attached to the right hepatic vein (Figure 1). After careful analysis of the CT scan, it became clear that the proximal part of the middle hepatic vein was completely missing, whereas its distal branches seemed to be open. In order to get more detailed information about the anatomical situation, an additional 3D imaging of this case was performed. It was evident that the middle hepatic vein was missing. Most likely this anatomical pattern was not tumour related because there was a close proximity of metastasis and right hepatic

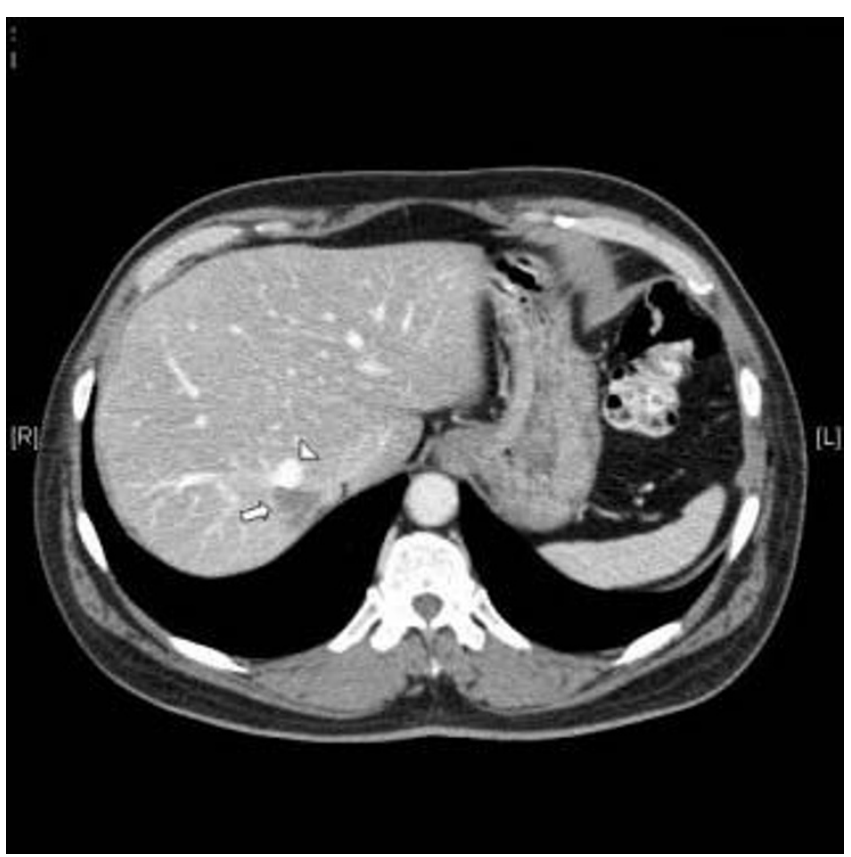

Figure I

Transversal CT image of the patient's liver showing the right (arrowhead) in proximity to the tumor (arrow).

vein (Figure 2) making the resection of the right hepatic vein inevitable. As the non-existence of a middle hepatic vein may have led to insufficient drainage of remnant hepatic parenchyma following a bisegmental resection of CS 6 and 7, it was decided to perform a right-sided hemihepatectomy. The pathologic examination confirmed the diagnosis of a colorectal liver metastasis. The surrounding liver parenchyma did not show any distinctive features, and in particular, no evidence of liver cirrhosis. The intraand postoperative courses of the patient were uneventful. The patient was discharged on the eighth postoperative day.

\section{CT scans}

The according CT scan was made available by the Radiology Department of the German Cancer Research Center, Heidelberg. The image data was acquired preoperatively during the routinely performed CT scan.

\section{Image data}

Image data were acquired with a Toshiba Aquilion 16 slice multidetector CT scanner (Toshiba, Japan). A standard bior triphasic liver scan with an optimized portal venous phase was performed. SureStart bolus tracking technique (130 ml Imeron 300, Altana, Germany, flow rate 4-5 ml/ s) was used in all protocols to optimize vascular contrast [26]. 


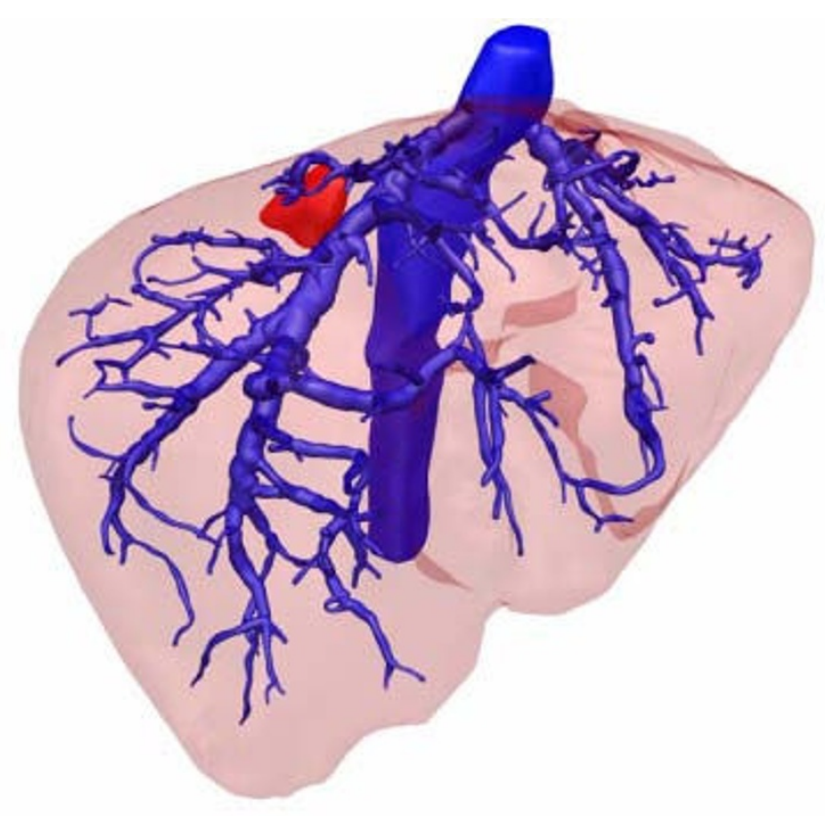

Figure 2

3D visualization of the venous anatomy. The observer has a view from above the liver. Here, the proximal part of the middle hepatic vein is missing. The tumor is colored in red.

\section{Data transfer and digital postprocessing}

Imaging data sets were transferred to the Department of Medical and Biological Informatics of the German Cancer Research Center using the CHILI [23] teleradiology system (CHILI GmbH, Heidelberg, Germany). Segmentation of the liver was performed using interactive region growing techniques as previously described by our group [6]. The vessels were segmented using a grey-value-based volume-growing technique. The segmentation was then transformed automatically into a symbolic representation of the vascular anatomy containing the vessel paths, and locations of bifurcations as well as the vessels diameters [24]. The origin of the left, middle, and right hepatic veins were identified, clicked upon and all depending vessels were marked automatically as branches of that particular vein. Portal veins and arteries were defined in the same manner. All results were validated by a team consisting of surgeons, radiologists and medical computing specialists.

Since the whole process from CT data to $3 \mathrm{D}$ viszualization preserves all positional information, $3 \mathrm{D}$ visualization and original CT data can be presented in a consistent manner. Several tools are available for the interactive exploration of the individual patient anatomy. One of these tools, the "re-localization tool", allowed us to define any volume element (voxel) in the CT scan and find this particular voxel within the $3 \mathrm{D}$ visualization. This is of special impor- tance because the localization of intrahepatic venous shunts is more easily achieved with the help of 3D images.

\section{Conclusion}

Even though $3 \mathrm{D}$ visualization is now available for a couple of organ systems, the technique must still be described as rather new [25-27]. It has been shown in the field of liver surgery that $3 \mathrm{D}$ visualization leads to a better understanding of the liver anatomy and in turn improves surgical operation planning $[1,2]$. In order to optimize the conception of the anatomical situation and thereby potentially improve patient safety, we routinely perform 3D analyses in preparation for liver surgery in patients with complicated liver anatomy and/or demanding surgical procedures including living-related liver transplantation [4].

The 3D images of the here presented data showed a missing middle hepatic vein (Figure 3A). Interestingly, the distal branches of the middle hepatic vein were still open and served as the origin of intervenous anastomoses to both the left and right hepatic veins (Figure 3B). Overall, six IVA were detectable, two to the left hepatic vein and four to the right hepatic vein. Because the proximal part of the middle hepatic vein was not detectable intraoperatively, one could speculate that the anatomical situation represents an anatomical variation rather than an after-effect of an old thrombosis.

Even though the CT images were sufficient to detect IVA, the $3 \mathrm{D}$ visualization improved the ability to detect IVA (Figures 3A and 3B), especially by using the features of the relocalization tool (description in Materials and Method section) which enables parallel searching for IVA in the CT scan and the $3 \mathrm{D}$ visualization. This parallel approach enabled us to detect intrahepatic anastomoses which could have been missed if only two-dimensional CT scans had been examined (figures $3 \mathrm{~A}$ and $3 \mathrm{~B}$ ). Further, within the freely movable $3 \mathrm{D}$ images, the IVA could be detected very easily and fast. In contrast, the determination of IVA is time consuming with two-dimensional CT scans because one has to go back and forth within the image slices to follow the course of the IVA in order to find their drainage vessels.

The here presented data suggests that the information offered by $3 \mathrm{D}$ visualization is not redundant but rather serves as a true source of additional information especially in patients with complicated liver anatomy.

\section{Consent}

Written informed consent was obtained from the patient for publication of this case report and any accompanying images. A copy of the written consent is available for review by the Editor-in-Chief of this journal. 

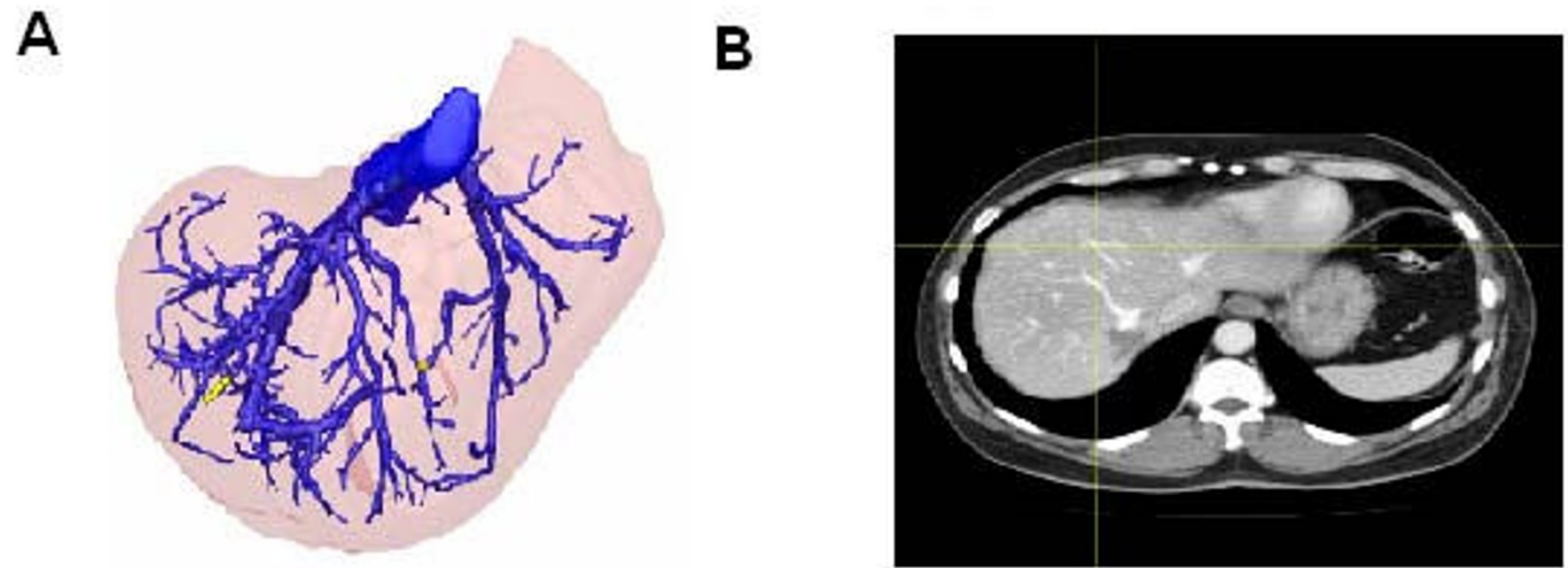

Figure 3

A: 3D visualization of an intrahepatic shunt between the distal part of the middle hepatic vein and the right and left hepatic veins. Since both CT images and 3D images are based on the same data set, every volume element (voxel) is uniquely defined in all three dimensions ( $x-, y$ - and $z$-axes). Our operations planning system allows us to identify the exact same voxel in both representations, i.e. in CT scans and 3D visualization. Here, the arrow directs to the yellow dot that is set as the original landmark in the 3D image. B: The crosshairs point to the exact same position as the yellow dot shown in figure $3 \mathrm{~A}$, indicating the position of the identical intrahepatic anastomosis in the CT image. One can speculate whether this vessel structure would have been correctly identified as an intravenous anastomosis if only the CT rather than the 3D images had been available.

\section{Competing interests}

The authors hereby confirm that there exists no competing interest regarding their personal or financial relationship with other people or organizations. The authors disclose any financial competing interests but also any non-financial competing interests that may cause them embarrassment were they to become public after the publication of the manuscript.

\section{Authors' contributions}

LF and BMS both conceived of the case report and drafted the manuscript. MS and H-PM post processed the image data to 3D images. SM and JON collected the patient's data and patients informed consent. MWB was involved in the planning of the study and the critical revision of the manuscript for important intellectual content. All authors read and approved the final manuscript.

\section{References}

I. Lamade W, Glombitza G, Fischer L, Chiu P, Cardenas CE Sr., Thorn M, Meinzer HP, Grenacher L, Bauer H, Lehnert T, Herfarth C: The impact of 3-dimensional reconstructions on operation planning in liver surgery. Arch Surg 2000, I35: I256-I26I.

2. Herfarth C, Lamade W, Fischer L, Chiu P, Cardenas C, Thorn M, Vetter $M$, Grenacher L, Meinzer HP: The effect of virtual reality and training on liver operation planning. Swiss Surg 2002, 8:67-73.

3. Mastrangelo MJ Jr., Adrales G, McKinlay R, George I, Witzke W, Plymale M, Witzke D, Donnelly M, Stich J, Nichols M, Park AE: Inclusion of 3-D computed tomography rendering and immersive VR in a third year medical student surgery curriculum. Stud Health Technol Inform 2003, 94:199-203.

4. Wente MN, Thorn M, Radeleff B, Dei-Anane G, Mehrabi A, Sauer P, Buchler MW, Schmidt J, Kraus TW, Schemmer P: A routine liver transplantation in a patient with situs inversus: a case report and an overview of the literature. Clin Transplant 2006, 20: $|5|-155$.

5. Neumann JO, Thorn M, Fischer L, Schobinger M, Heimann T, Radeleff B, Schmidt J, Meinzer HP, Buchler MW, Schemmer P: Branching patterns and drainage territories of the middle hepatic vein in computer-simulated right living-donor hepatectomies. Am J Transplant 2006, 6: |407-14 I5.

6. Fischer L, Thorn M, Neumann JO, Schobinger M, Heimann T, Grenacher L, Meinzer HP, Friess H, Buchler MW: The segments of the hepatic veins-is there a spatial correlation to the Couinaud liver segments? Eur J Radiol 2005, 53:245-255.

7. Glombitza G, Evers H, Hassfeld S, Engelmann U, Meinzer HP: Virtual surgery in a (tele-)radiology framework. IEEE Trans Inf Technol Biomed 1999, 3:186-196.

8. Fischer L, Cardenas C, Thorn M, Benner A, Grenacher L, Vetter M, Lehnert T, Klar E, Meinzer HP, Lamade W: Limits of Couinaud's liver segment classification: a quantitative computer-based three-dimensional analysis. J Comput Assist Tomogr 2002, 26:962-967.

9. Oldhafer KJ, Preim B, Dorge C, Peitgen HO, Broelsch CE: [Acceptance of computer-assisted surgery planning in visceral (abdominal) surgery]. Zentralbl Chir 2002, I 27:128-133.

10. Ritter F, Hansen C, Dicken V, Konrad O, Preim B, Peitgen HO: Realtime illustration of vascular structures. IEEE Trans Vis Comput Graph 2006, I 2:877-884.

II. Lang H, Radtke A, Liu C, Sotiropoulos GC, Hindennach M, Schroeder $T$, Peitgen HO, Broelsch CE: Improved assessment of functional resectability in repeated hepatectomy by computer-assisted operation planning. Hepatogastroenterology 2005, 52: I 645-I648.

12. Couinaud C, Noguiera C: Les Veines Sus-Hépatiques Chez I'Homme. Acta Anat 1958, 34:84-I I0. 
13. Masselot R, Leborgne ]: Anatomical study of the hepatic veins. Anat Clin 1978, I:109-125.

14. Guntz M: Anatomie et radio-anatomie. Trav lab Anat Fac Med 1959.

15. Cescon M, Sugawara Y, Sano K, Ohkubo T, Kaneko J, Makuuchi M: Right liver graft without middle hepatic vein reconstruction from a living donor. Transplantation 2002, 73: I I64- I I66.

16. Kaneko T, Kaneko K, Sugimoto H, Inoue S, Hatsuno T, Sawada K, Ando $\mathrm{H}$, Nakao $\mathrm{A}$ : Intrahepatic anastomosis formation between the hepatic veins in the graft liver of the living related liver transplantation: observation by Doppler ultrasonography. Transplantation 2000, 70:982-985.

17. Sugimoto $H$, Kaneko T, Nakao A: Anastomosis between the middle and right hepatic vein. Hepatogastroenterology 2002, 49: $1257-1258$.

18. Sano K, Makuuchi M, Takayama T, Sugawara Y, Imamura H, Kawarasaki H: Technical dilemma in living-donor or split-liver transplant. Hepatogastroenterology 2000, 47:1208-I209.

19. Fried MP, Uribe JI, Sadoughi B: The role of virtual reality in surgical training in otorhinolaryngology. Curr Opin Otolaryngol Head Neck Surg 2007, 15:163-169.

20. Endo I, Shimada H, Takeda K, Fujii Y, Yoshida K, Morioka D, Sadatoshi S, Togo S, Bourquain H, Peitgen HO: Successful duct-to-duct biliary reconstruction after right hemihepatectomy. Operative planning using virtual 3D reconstructed images. J Gastrointest Surg 2007, I I:666-670.

21. Suzuki S, Eto K, Hattori A, Yanaga K, Suzuki N: Surgery simulation using patient-specific models for laparoscopic colectomy. Stud Health Technol Inform 2007, I 25:464-466.

22. Clarke JR, Marella W, Johnston J, Davis M: A surgeon who CARES can be safer. Am J Surg 2005, 190:356-358.

23. Engelmann U, Schwab M, Schroter A, Rusu P, Meinzer HP: [Evaluation of CHILI teleradiology network 4 years after clinical implementation]. Radiologe 2002, 42:87-93.

24. Meinzer HP, Thorn M, Cardenas C: Computerized planning of liver surgery - an overview. Computers \& Graphics 2002, 26:569-576.

25. Hallscheidt PJ, Thorn M, Radeleff BA, Noeldge G, Shab A, Meinzer P, Boese JM: Comparison of spatial resolution in high-resolution multislice computed tomography and digital subtraction angiography using renal specimens. J Comput Assist Tomogr 2003, 27:864-868.

26. Grenacher L, Thorn M, Knaebel HP, Vetter M, Hassenpflug P, Kraus T, Meinzer HP, Buchler MW, Kauffmann GW, Richter GM: [The role of 3-D imaging and computer-based postprocessing for surgery of the liver and pancreas]. Rofo 2005, 177:1219-1226.

27. De SR, Glombitza G, Vahl CF, Meinzer HP, Hagl S: Three-dimensional color Doppler flow reconstruction and its clinical applications. Echocardiography 2000, 17:765-771.
Publish with Biomed Central and every scientist can read your work free of charge

"BioMed Central will be the most significant development for disseminating the results of biomedical research in our lifetime. "

Sir Paul Nurse, Cancer Research UK

Your research papers will be:

- available free of charge to the entire biomedical community

- peer reviewed and published immediately upon acceptance

- cited in PubMed and archived on PubMed Central

- yours - you keep the copyright
BioMedcentral 